\section{"Lucubratory Biochemistry"}

UNDER this title a review of my biochemistry text-book was published in Nature of March 24, p. 544. The reviewer criticizes many of my statements by expressions such as "astonishing dictum", "Paradox indeed", or by other ironical remarks. A reply to each of the numerous comments would occupy much space. Therefore, only a few of them can be answered here.

The reviewer quotes as "interesting" the statement that natural isotopes are stable, and asks: "Has Dr. Haurowitz never heard of naturally occurring radioactive isotopes, for example of potassium or of carbon ?" It is not evident from the review that the statement criticized is made in a section on "Methods", in which only those isotopes are treated which are used as tracers in biochemical research. Obviously, the statement on the stability of natural isotopes applies only to isotopes of this type. Natural radioactive potassium and carbon, mentioned in the question of the reviewer, are not used as tracers. Potassium-42 and carbon-14, used in tracer work, are produced artificially. The obvious answer to the first part of the question asked by the reviewer is that every high-school boy knows about the occurrence of uranium and of other radioactive isotopes in Nature. One may wonder why the question was asked.

The review contains the following comment : "On p. 132 the statement is made, "The amino acids are colorless substances that are soluble in water', although later the insolubility of cystine in water is mentioned (p. 156)". On p. 156 I wrote : "Cystine, in contrast to cysteine, is almost insoluble in water". Omission of the word "almost" creates here a contradiction.

Another comment refers to the following words of my book : "Attempts to prepare estrogenic hormones synthetically, led to the unexpected result that certain stilbene derivatives, such as dihydroxydiethylstilbene, are just as active as estradiol". This - statement is criticized as "historically incorrect, as can be seen by consulting the early papers of Dodds and his collaborators". Dodds and his co-workers, in their paper on the estrogenic activity of stilbene derivatives (Proc. Roy. Soc., 127, p. 140), wrote: ". . . in view of the difficulties presented by the total synthesis of the naturally occurring œestrogenic hormones, attempts were made to prepare more accessible substances the molecules of which would be similar to ostradiol in shape, weight and in the situation of the hydroxyl groups". Readers of Nature will now be able to judge whether my presentation was "historically incorrect".

More than a dozen examples of a similar type could be added. They would not show more than the three examples given above, namely, that most of the comments of the reviewer are hypercritical and that the text of my book is not so inadequate as it may appear to those who read only the review in Nature.

\section{Department of Chemistry, Indiana University,}

Bloomington, Indiana. Aug. 5.

SrNce my review was critical, I attempted to be as fair as possible by quoting at length some of the extracts with which I did not agree. I do not believe that any useful purpose can be served by arguing about individual points, although I could take up each of the comments which Prof. Haurowitz has made. I am content to leave those who wish to judge whether my review was fair or not to read it in relation to the book itself.

\section{Department of Biochemistry, University of Cambridge.}

F. G. Young

\section{A Word Common to the Natives of Alaska, Canada, Greenland and Brazil}

Dr. NICHolas Polunin has suggested that I should direct the attention of botanists and others to the ancient provenance of a word which appears to moan fundamentally 'the juice of a plant that is used for chewing', as a chewing gum.

Not being English or French, but of speech a midwest American from Manitoba and Dakota, it did not mean anything to me when in $1906 \mathrm{I}$ heard the Eskimos of the Mackenzie Delta and north-eastern Alaska speaking of spruce gum as 'kutsuk'. They used to fetch this themselves from the evergreen forest to the south or buy it from the forest Indians; more recently, they had been buying flavoured chewing gum from the whalers, which they also spoke of as 'kutsuk', as they did of a substitute of their own, dried seal blood, which they said they "always" used in the pre-white days if they ran out of spruce gum for their children to chew.

Years later, perhaps in 1912, I learned that the word for the gum of a Brazilian plant, and of other South American plants, is 'caoutchouc', and the Oxford Dictionary defines it as "a milky resinous juice of certain trees in S. America ....". The Oxford Dictionary goes on to connect the derivation of this word for rubber with a French expedition to the Amazon country in 1739. 'Webster' has the same tale, more briefly, and gives varied spellings, among them 'caucho' and 'gutteux'. I like the last best, for it is nearest to what I have heard among the Eskimos from Bering Strait to Coronation Gulf. 'They said 'gutsuk', the $s$ as always in their tongue with an $s h$ - sound.

Turning now to Greenland, in Sam. Kleinschmidt : "Den Grönlandske Ordbog" (Copenhagen, 1871), I find "kutsuk. (1) Harpix (det almindelege, af Naaletraeer; (2) hvad der paa samme Maade udsondrer sig i andre Traeer : Gummi, Campher og lignende producter". Schultz-Lorentsen's "Dictionary of the West Greenland Eskimo Language" (Copenhagen, 1927) has only: "kutsuk, resin, gum".

So we appear to have in the New World a term for the gum of a plant which people use for chewing and call by the same name from Greenland to Alaska to Brazil. When I first began to talk about this, I was told it was coincidence. But the intellectual climate is changing, among other things in linguistics, and now the disciples of men like Uhlenbeck and Hammerich think 'connexion' a likelier word than 'coincidence'. Incidentally, I found the Eskimos saying 'ignirk' for fire and I know that the Romans said 'ignis'; but again my linguist friends said 'coincidence'; now I believe the followers of Uhlenbeck think we have in this a connexion from the Sanskrit to the Latin to the Eskimo.

Dartmouth College, VILHJALMUR STEFANSSON

Hanover, New Hampshire. 